\title{
Welcome Speech
}

\author{
Bambang Hidayat \\ Bosscha Observatory and Department of Astronomy, ITB, Bandung, \\ Indonesia
}

Distinguished guests, colleagues, and participants:

As all of you already know, 22 years have elapsed since the Hamburg meeting on the Schmidt Telescope in 1972. Since that time, two other meetings have preceeded our present gathering: one in 1984 held at Asiago, Italy and the other, in 1993, in Potsdam, Germany. At those meetings discoveries and results obtained with Schmidt Telescopes were presented together with discussions on the future uses of the telescopes. Many of those results are monuments to our scientific understanding during the respective periods. About 60 per cent of the papers presented in 1984 dealt with the future uses of the Schmidt telescope. Some, such as those on the automisation of the normally abundant data collected with Schmidt telescopes, are prophetically valid for now and the future.

So why are we talking again about Schmidts? Not only do scientific needs continue to change, but also the technological environment. This dictates careful reconsideration of the path of Schmidt astronomy in the future. I am not going to elaborate on this as this topic will be discussed by Dr Cannon in his introduction. The need to hold another meeting on Schmidt telescopes is clearly a recognition of the importance of Schmidt astronomy. In view of the many important results given at the Symposium on Wide-Field Imaging in Potsdam, our responsibility is large. It is now up to us to consider carefully the right and proper utilisation of some sixty-nine Schmidt telescopes around the world.

Many individuals and organizations have helped bring this meeting to fruition. Firstly, I wish to convey our deep appreciation to the members of the Scientific Organizing Committee who have identified seventeen main topics for discussion. These appear in the programme book. Each of the sessions is hoped to provide input for the future utilisation of Schmidt Telescopes.

I would like to express our gratitude to the Executive Committee of the International Astronomical Union for having accepted our proposal to organize this colloquium here in Bandung. We thank the IAU in particular for providing financial suppport which has enabled many colleagues from abroad to attend the meeting. We also thank Mr S. Tando (Patrabuilds) and the Deutsches Akademisch Austausch Dienst, Jakarta, who provided financial support for several overseas astronomers to attend.

The Indonesian National Committee for UNESCO has been very helpful in supporting this meeting. We would like to thank the chairman of the National Committee for UNESCO for his determination to obtain the UNESCO acceptance. Special thanks also go to the Indonesian Institute of Sciences (LIPI 
- the adhering body to the IAU Leids-Kerkhoven Bosscha Foundation in the Netherlands), for their interest in this colloquium.

We thank the Directorate General of Higher Education of the Department of Education and Culture, Dr Haryanto Dhanutirto - the minister of transportation, Mr J. Parapk - the Secretary General of the Ministry of Tourism, Post and Telecommunication and Mr Moh Hasan (MPI) for providing facilities and financial support.

We thank P. T. Gudang Garam, the cigarette factory in East Java which has provided financial assistance for this and several previous international astronomy meetings, and to Astragraphia, who assisted with reproduction matters.

We thank the automotive industry, P. T. Astra International and Mr Bambang Salistyo of the Indonesian Communication Satellite Enterprise (Indosat), who have provided support to make our stay at the Hotel Savoy Homann more enjoyable. The daily newspaper "Kompass", as in the past, has assisted financially with local expenses and with accommodation. We express our appreciation to Mr Jakob Oetama, the chairman of Kompass. We also thank the local daily newspaper "Pikiran Rakyat", who together with the local organizzing committee, arranged the public lectures, and Mr Suharmono Tjitrosoewarno, a corporate member of Pikiran Rakyat who helped with accommodation costs.

We have arranged a midday talk on the Indonesian satellite, Palapa. This satellite was launched twenty years ago, and has provided a stronger bond between the many diverse ethnic and cultural groups in the Indonesian archipelago. We thank Telkom for coming to tell us about the success of Palapa and for other assistance. We thank Dr David Malin (Anglo-Australian Observatory) who will be giving an after dinner speech on "Colour in the Universe", and Drs D. J. MacConell and B. Lasker (STScI), who will give an after dinner speech on the Hubble Space Telescope.

We express our appreciation to Mr F. Muhammed (P. T. Bukaka) and Mr R. Danuningrat (Head of PTP X111) who have helped to prepare the cultural evenings and a half day excursion to the Bosscha family tea plantation, and the Govenor of West Java who will be hosting a cultural evening on March 7 th. Finally the LOC wishes to thank the office of the President (BINAGRAHA), for providing the first instalment of a data processing system and Local Area Network. The installation will be continued in the coming months and will be of great use to astronomers.

The time of our meeting takes place in the middle of the month of Ramadhan - we call it puasa (to fast). This has some consequences. In our belief, good undertakings with sincere intentions, held during Ramadhan are regarded as Ibadah and will receive God's blessing. I hope this is true for our present deliberations. Also the end of our meeting, on March 11th, happens to coincide with an important date in our nation's history. I sincerely hope that it will also add to the value of our meeting.

Although religious tolerance in Indonesia is boundless, we naturally are obliged to honour our colleagues who are fulfilling their religious duties. We have tried to do everything to conform with the accepted set of values of Ramadhan. If you happen to spot some of our committee members seeming sleepy in the 
day time, please remember that he or she may be contemplating, rather than anything else.

Naturally, we are delighted to welcome you from distant places to this montainous part of Java. This geographic location will, I hope, provide you with cooler air than that of Jakarta; and will fuel your stamina for the coming deliberations. Please forgive us for our shortcomings and unintentional omissions.

During the preparation of this colloquium the committee has received support from many individuals and organizations. Members of the SOC and LOC have worked hard to make this happening possible. We thank all of you who have helped us. Among the individuals who stand out in this is Sandra Harrison. Thank you very much, Sandra. Without you and your fax, E-mail, and phone we would not be here today.

B. Hidayat 